Chapter 2

\title{
Modeling of Ionic Liquid Systems: Phase Equilibria and Physical Properties
}

\author{
Filipa M. Maia, Noelia Calvar, Emilio J. González, \\ Aristides P. Carneiro, Oscar Rodriguez and \\ Eugénia A. Macedo
}

Additional information is available at the end of the chapter

http://dx.doi.org/10.5772/51812

\section{Introduction}

Ionic liquids (ILs) are a class of salts with a melting temperature below $100{ }^{\circ} \mathrm{C}$, and the study of these compounds is considered priority by the U.S. Environmental Protection Agency. Due to their specific properties, which can be adjusted by changing either the cation or the anion, ILs have received great attention by the scientific community as potential replacements for volatile organic solvents (VOCs), and nowadays, ILs are starting to leave academic labs and find their way into a wide variety of industrial applications [1]. For example, ILs are used for the dispersion of nano-materials at IOLITEC, Air Products uses ILs instead of pressurized cylinders as a transport medium for reactive gases, ION Engineering is commercializing technology using ILs and amines for $\mathrm{CO}_{2}$ capture and natural gas sweetening, and many others.

In order to apply these new compounds in different processes, the study of their physical properties, pure or mixed with other solvents, and phase equilibria (vapor-liquid, liquid-liquid, and solid-liquid equilibria) is crucial from a technological point of view. For example, density is fundamental to develop equations of state and it is also required for the design of different equipments, while viscosity is necessary for the design of processing units and pumping systems, and to study heat and mass transfer processes [2]. On the other hand, the refractive index can be used as a measure of the electronic polarizability of a molecule and can provide useful information when studying the forces between molecules or their behavior in solution [3]. 
As known, ILs also show an interesting potential to be used in separation processes and extraction media. Therefore, the knowledge of the mutual solubilities of molecular solvents and ILs prior to their industrial applications is also of primary importance. Moreover, many factors that control the phase behavior of these ionic salts with molecular solvents may be described from the phase equilibrium data.

However, as the number of possible ILs is enormous, this cannot be accomplished via experimental determination. Thus, it is very important to obtain models or empirical equations able to describe satisfactorily the experimental data.

In this chapter, a revision of the different equations applied for the modeling of physical properties of pure ILs and their mixtures, and phase equilibria of binary and ternary mixtures containing ILs, is presented and discussed. Future trends regarding the use of new models, namely equations of state accounting for association effects, are also focused.

\section{Physical properties}

\subsection{Pure ionic liquids}

Since ILs are relatively new compounds, experimental data on physical properties, such as density, viscosity, or refractive index of pure ILs and its mixtures with other solvents are required for the design of different equipment and processing units and very useful for developing accurate theoretical models.

Due to innumerable number of ILs that can be synthesized, experimental measurements are impractical for selection of a suitable IL for a specific application. Therefore, development of correlations and theoretical approaches allowing accurate modeling of IL-based systems is essential. This section shows the most common empirical equations used to correlate the temperature dependence of some of the physical properties of ILs.

For pure ILs, temperature dependence of physical properties such as density, speed of sound, or refractive index is very important for the successful and large-scale use of these compounds. Usually, this dependence is described using simple polynomial expressions, mainly equations of first, second and third order [4-6].

Several papers were also published concerning the experimental densities of pure ILs as a function of temperature and pressure [6-9]. The Tait equation [10] with four adjustable parameters is commonly used to fit these experimental data [6,8]. This equation is an integrated form of an empirical equation representative of the isothermal compressibility behavior versus pressure, and it can be expressed as:

$$
\rho(T, p, C, B)=\frac{\rho(T, 0.1 \mathrm{MPa})}{1-C \cdot \operatorname{Ln}\left(\frac{B(T)+p}{B(T)+0.1 \mathrm{Mpa}}\right)}
$$

where $\rho(T, 0.1 \mathrm{MPa})$ represents the temperature dependence of density at $0.1 \mathrm{MPa}$. $C$ is an adjustable parameter, and $B(T)$ is commonly expressed as a second-order polynomial: 


$$
B(T)=\sum_{i=0}^{2} B_{i} \cdot T^{i}
$$

Regarding the variation of viscosity with temperature for pure ILs, a large number of empirical equations for correlating this property of pure fluids and mixtures can be found in literature $[4,5,11-14]$. The most commonly used equation is an Arrhenius-like law:

$$
\eta=\eta \cdot \exp \left(-\frac{E_{\mathrm{a}}}{R T}\right)
$$

where the viscosity at infinite temperature $\left(\eta_{\infty}\right)$ and the activation energy $\left(E_{\mathrm{a}}\right)$ are characteristic parameters generally adjusted from experimental data.

According to Seddon et al. [15], the Arrhenius law can generally be applied when the cation presents only a limited symmetry. If it is not the case, and especially in the presence of small and symmetrical cations with low molar mass, other equations such as the Vogel-FulcherTamman (VFT) equation [16-18], or the modified VFT (mVFT) equation are recommended. This kind of expressions includes an additional adjustable temperature parameter $\left(T_{0}\right)$ to the exponential term:

$$
\begin{gathered}
\eta=A \cdot \exp \left(\frac{B}{T-T_{0}}\right) \\
\eta=A \cdot T^{0.5} \cdot \exp \left(\frac{B}{T-T_{0}}\right)
\end{gathered}
$$

where $A$ and $B$ are also adjustable parameters.

Another empirical equation to correlate viscosity data with temperature was proposed by Litovitz [19]:

$$
\eta=A \cdot \exp \left(\frac{B}{R T^{3}}\right)
$$

This equation is used at ambient pressures and has the advantage of containing only two fitting parameters. Comparing all these equations, in general, the best fits for the variation of viscosity with temperature for pure ILs are obtained with the VFT equation [5].

As reflected by Harris et al. [11], the general form of the pressure dependence of the shear viscosity of liquids is greater than exponential at moderate pressures and less than exponential at very high pressures. Taking this into account, these authors modified the VFT and Litovitz equations in order to include the temperature and pressure dependence of the viscosity for several pure imidazolium-based ILs. The new equations were defined as:

$$
\eta=\exp \left(A+B p+\frac{\left(C+D p+E p^{2}\right)}{T^{3}}\right)
$$




$$
\eta=\exp \left(A^{\prime}+B^{\prime}+\frac{\left(C^{\prime}+D^{\prime} p+E^{\prime} p^{2}\right)}{T-T_{0}}\right)
$$

As for the density, a Tait-form equation is also used to correlate the pressure dependence of viscosity demonstrating good correlations [12,13].

$$
\frac{\eta(T, p, C, B)}{\eta(T, 0.1 \mathrm{MPa})}=\exp \left(C \cdot \operatorname{Ln}\left(\frac{B(T)+p}{B(T)+0.1 \mathrm{Mpa}}\right)\right)
$$

where $\eta(T, 0.1 \mathrm{MPa})$ represents the temperature dependence of viscosity at $0.1 \mathrm{MPa} . C$ is an adjustable parameter, and $B(T)$ is also commonly expressed as a second-order polynomial.

A hybrid Tait-Litovitz equation at elevated pressures (up to $126 \mathrm{MPa}$ ) was also presented in the literature to correlate the viscosity data for a series of room-temperature ILs [14]. The Litovitz equation is firstly used to correlate the data at ambient pressure, and then the Tait parameters are fitted for the higher pressures. This equation has the advantages of containing fewer fitting parameters than other models and simplicity of data analysis. The results show a good fit between the experimental data and those predicted by this equation.

\subsection{Binary and ternary mixtures}

In order to better understand the nature of ILs and design any future technological processes, detailed knowledge on the physical properties of ILs mixed with other solvents is required. During the last few years, the number of studies on thermophysical and thermodynamic properties of pure ILs and their mixtures with molecular solvents has increased significantly [4,20-24].

As for pure ILs, the dependence of the physical properties with temperature and composition is also correlated using empirical equations. In general, the change of density, speed of sound, refractive index and viscosity with composition is typically fitted to a polynomial expression although other more specific equations can be also found in literature. As example, the Connors and Wright equation [25] is employed to describe the variation of density with composition:

$$
\rho=\rho_{1}-\left[1+\frac{b x_{1}}{\left(1-a x_{1}\right)}\right]\left(1-x_{1}\right)\left(\rho_{1}-\rho_{2}\right)
$$

where $\rho_{1}$ and $\rho_{2}$ are densities of pure compounds; $x_{\mathrm{i}}$ is the mole fraction of component $i$ of the mixture; and $a$ and $b$ are fitting parameters. Although this equation was initially adopted only for the concentration dependencies of surface tension, Geppert-Rybczynska et al. [20] employed this equation for density getting a fit better than using any other simple polynomial.

As it is known, the above mentioned physical properties can be used to obtain the corresponding excess properties, which are generally fitted to a Redlich-Kister type equation [26]: 


$$
\delta Q=x_{1}\left(1-x_{1}\right) \sum_{\mathrm{i}=0}^{M} A_{\mathrm{i}}\left(2 x_{1}-1\right)^{\mathrm{i}}
$$

where $\delta Q$ is the excess property, $x$ is the mole fraction, $A_{\mathrm{i}}$ are the adjustable parameters and $M$ is the degree of the polynomial expansion.

An extended version of the Redlich-Kister equation, which takes into account the dependence on composition and temperature simultaneously, is also used to fit the excess properties [22]:

$$
\delta Q=x_{1}\left(1-x_{1}\right) \frac{\sum_{\mathrm{i}=0}^{M} A_{\mathrm{i}}\left(2 x_{1}-1\right)^{\mathrm{i}}}{1+\sum_{j=1}^{N} B_{j}\left(2 x_{1}-1\right)^{j}}
$$

In order to take into account the influence of temperature on the excess properties, all the coefficients $A_{\mathrm{i}}$ and $B_{\mathrm{i}}$ are usually expressed as a second-order polynomial.

Density, refractive index, and viscosity data for ternary mixtures containing ILs are also common in the literature [27-29] and they are usually fitted to polynomial expressions. In these cases, weight fractions are often used instead of mole fractions, due to the large difference of molar mass between ILs and most organic solvents.

For the modeling of the excess properties, such as excess molar volumes, viscosity deviations, refractive index deviations or excess free energies of activation of viscous flow, the use of empirical equations is commonly adopted. Although the Redlich-Kister equation is also applied to correlate the excess properties for ternary systems containing ILs [29], the equations more widely employed are those proposed by Cibulka [30], Singh et al. [31] and Nagata and Sakura [32]. All the correlative models are capable of representing the behavior of the ternary mixtures with a higher or lesser degree of accuracy, although that developed by $\mathrm{Ci}$ bulka usually leads to a better agreement with experimental data [28].

Cibulka equation:

$$
Q_{123}^{\mathrm{E}}=Q_{12}^{\mathrm{E}}+Q_{13}^{\mathrm{E}}+Q_{23}^{\mathrm{E}}+x_{1} x_{2} x_{3}\left(A+B x_{1}+C x_{2}\right)
$$

Singh et al. equation:

$$
Q_{123}^{\mathrm{E}}=Q_{12}^{\mathrm{E}}+Q_{13}^{\mathrm{E}}+Q_{23}^{\mathrm{E}}+A x_{1} x_{2} x_{3}+B x_{1}\left(x_{2}-x_{3}\right)+C x_{1}^{2}\left(x_{2}-x_{3}\right)^{2}
$$

Nagata and Sakura equation:

$$
Q_{123}^{\mathrm{E}}=Q_{12}^{\mathrm{E}}+Q_{13}^{\mathrm{E}}+Q_{23}^{\mathrm{E}}+x_{1} x_{2} x_{3} A
$$


where $A, B$ and $C$ are fit parameters and $Q_{\mathrm{ij}}^{\mathrm{E}}$ is the contribution to the excess property of the constituent binary mixtures evaluated by Redlich-Kister equation.

\section{Phase equilibria}

Despite the large number of published articles and the broad fields of applications, there has not been a model explicitly derived for phase equilibria of ILs. This lack of models intended for systems containing ILs has forced researchers to use the equations available. But these equations were intended for ionic solutions, or not intended for ions at all. Thus, a model to account for a medium which is composed of ions, without a molecular solvent, is still needed. Nevertheless, the phase equilibria of ILs and their mixtures are being modeled in the literature. The models used will be described ahead. In general, those based on the excess Gibbs energy such as Wilson, NRTL or UNIQUAC were the first to appear. Lately, models with modifications for association (UNIQUAC ASM, NRTL1) and for electrolytes (PDH, eNRTL) were also applied for this kind of systems in order to improve the results obtained with the initial models. Besides, Equations of State (EoS) have also been applied, especially for mixtures with gases and for broad ranges of pressure.

\section{1. $\mathrm{g}^{\mathrm{E}}$-based models}

Most of the $\mathrm{g}^{\mathrm{E}}$ models available in the literature are for non-electrolytes. Thus, many authors have been using these models, or models for electrolyte solutions, for the phase equilibria of systems containing ILs. For example, for binary systems containing ILs it is common to use the model developed by Debye-Hückel (which was derived for small salt concentrations), although it is not recommendable for solutions at high ionic concentration.

The models for the correlation of these experimental data can be split into two main groups: i) ion-interaction Pitzer models and ii) local composition models.

i. The model developed by Pitzer has created a new generation of theories which use multiparameter regression. In the ion-interaction Pitzer model [33] the ion-interaction parameters are dependent on temperature and pressure, and it takes into account the Debye-Hückel constant.

The three-parameter Pitzer-ion interaction model has been successfully used for modeling vapor-liquid data of mixtures of ILs with water [34-37] or with alcohol [38] and has the following form for a binary 1:1 electrolyte solution:

$$
\phi-1=f^{\phi}+m B^{\phi}+m^{2} C^{\phi},
$$

where

$$
f^{\phi}=-A_{\phi} I^{1 / 2} /\left(1+b I^{1 / 2}\right)
$$




$$
\begin{gathered}
A_{\phi}=(1 / 3)\left(2 \pi \mathrm{N}_{\mathrm{A}} d_{s}\right)^{1 / 2}\left(\mathrm{e}^{2} / 4 \pi \varepsilon_{0} \varepsilon k T\right)^{3 / 2}, \\
B^{\phi}=\beta^{(0)}+\beta^{(1)} \exp \left(-\alpha_{1} I^{1 / 2}\right)
\end{gathered}
$$

In these equations, $\beta^{(0)}, \beta^{(1)}$ and $C^{\phi}$ are ion-interaction parameters of the Pitzer model that are dependent on temperature and pressure, and $A_{\phi}$ is the Debye-Hückel constant for the osmotic coefficient on the molal scale. Also, $\mathrm{N}_{\mathrm{A}}$ is the Avogadro number, e is the proton charge, $\varepsilon_{0}$ is the permittivity of vacuum, and $k$ is the Boltzman constant. The term $I$ is the ionic strength in molality, $I=1 / 2 \sum m_{i} z_{i}^{2}$, where $m_{i}$ is the molality of $i^{\text {th }}$ ion and $z_{i}$ is the absolute value for $i^{\text {th }}$ ionic charge. The remaining symbols have their usual meanings. The values for constants $b$ and $\alpha$ were $b=1.2 \mathrm{~kg}^{1 / 2} \mathrm{~mol}^{-1 / 2}$ and $\alpha=2 \mathrm{~kg}^{1 / 2} \mathrm{~mol}^{-1 / 2}$, respectively.

In the last years, the Extended Pitzer model of Archer $[39,40]$, in which the third adjustable parameter in the Pitzer model is replaced by a two-parameter function depending on the ionic strength, has demonstrated its accuracy in modeling binary Vapor-Liquid Equilibria (VLE) of systems containing ILs. In this model, the equation for $B^{+}$is extended to:

$$
B^{\phi}=\beta^{(0)}+\beta^{(1)} \exp \left(-\alpha_{1} I^{1 / 2}\right)+\beta^{(2)} \exp \left(-\alpha_{2} I^{1 / 2}\right)
$$

and a new equation is introduced:

$$
C^{\phi}=C^{(0)}+C^{(1)} \exp \left(-\alpha_{3} I^{1 / 2}\right)
$$

In the previous equations, the ion interaction parameters of the extended Pitzer model of Archer are $\beta^{(0)}, \beta^{(1)}, \beta^{(2)}, C^{(0)}$ and $C^{(1)}$, dependent on temperature and pressure, and $\alpha_{1}, \alpha_{2}$, $\alpha_{3}$, and $b$ can be adjustable parameters or kept fixed at constant values; they are usually fixed to the values: $\alpha_{1}=2 \mathrm{~kg}^{1 / 2} \mathrm{~mol}^{-1 / 2}, \alpha_{2}=7 \mathrm{~kg}^{1 / 2} \mathrm{~mol}^{-1 / 2}, \alpha_{3}=1 \mathrm{~kg}^{1 / 2} \mathrm{~mol}^{-1 / 2}$ and $b=3.2$ [41-44], although other values can be used [45]. This model is widely used in literature for binary mixtures containing ILs and water or alcohol or acetonitrile [46-55] with very satisfactory results.

ii. The local composition (LC) models give a better empirical description and have physical meaning for the correlation of osmotic and activity coefficients. There are several LC models reported in literature for the modeling of phase equilibria experimental data; such as UNIversal QUAsiChemical (UNIQUAC) [56], Non-Random Two Liquids (NRTL) [57], electrolyte NRTL (e-NRTL) [58], Non-Random Factor (NRF) [59], modified NRTL (MNRTL) [60], Mean Spherical Approximation NRTL (MSA-NRTL) [61] or Extended Wilson (EW) [62]. Furthermore, models with modifications for association such as UNIQUAC ASM or NRTL 1 are also applied for this kind of systems, although their use is less common $[63,64]$.

In local composition models it is assumed that the activity coefficient is composed by two terms: a long-range contribution (LR) and a short-range contribution (SR):

$$
\ln \gamma_{i}=\ln \gamma_{i}^{L R}+\ln \gamma_{i}^{S R}
$$


The well-known models of UNIQUAC and NRTL calculate the activity coefficients as follows:

ii.i In the UNIQUAC model [56], the long-range contribution term is expressed as:

$$
\ln \gamma_{\mathrm{i}}^{\mathrm{LR}, \text { UNIQUAC }}=\ln \left(\frac{\phi}{x_{\mathrm{i}}}\right)+\frac{\mathrm{z}}{2} q_{\mathrm{i}} \ln \left(\frac{\theta_{\mathrm{i}}}{\phi_{\mathrm{i}}}\right)+l_{\mathrm{i}}-\frac{\phi_{\mathrm{i}}}{x_{\mathrm{i}}} \sum_{\mathrm{j}=1}^{\mathrm{N}} x_{\mathrm{j}} \mathrm{l}_{\mathrm{j}}
$$

where the term $l_{\mathrm{i}}$ is defined as a function of the external surface of the molecule and the bond segments:

$$
l_{\mathrm{i}}=\frac{\mathrm{z}}{2}\left(r_{\mathrm{i}}-q_{\mathrm{i}}\right)-\left(r_{\mathrm{i}}-1\right)
$$

and the coordination number, $\mathrm{z}$, is set to 10 .

The short-range contribution in this model is expressed as:

$$
\ln \gamma_{\mathrm{i}}^{\text {SR,UNIQUAC }}=q_{\mathrm{i}}\left[1-\ln \left(\sum_{\mathrm{j}} \theta_{\mathrm{j}} \tau_{\mathrm{ji}}\right)-\sum_{\mathrm{j}=1}^{\mathrm{N}} \frac{\theta_{\mathrm{j}} \tau_{\mathrm{ij}}}{\sum_{\mathrm{k}} \theta_{\mathrm{k}} \tau_{\mathrm{kj}}}\right]
$$

The expression for the energy parameter, $\tau_{\mathrm{ij},}$ the volume fraction, $\phi_{\mathrm{i}}$, and the surface fraction, $\theta_{\mathrm{i}}$, are given for the next equations:

$$
\begin{gathered}
\tau_{j i}=\exp \left(-\frac{u_{j i}-u_{i i}}{R T}\right)=\exp \left(\frac{\Delta u_{i j}}{R T}\right) \\
\theta_{\mathrm{i}}=\frac{q_{\mathrm{i}} x_{\mathrm{i}}}{\sum_{\mathrm{j}} q_{\mathrm{j}} x_{\mathrm{j}}} \phi_{\mathrm{i}}=\frac{r_{\mathrm{i}} x_{\mathrm{i}}}{\sum_{\mathrm{j}} r_{\mathrm{j}} x_{\mathrm{j}}}
\end{gathered}
$$

where $u_{\mathrm{ij}}$ and $u_{\mathrm{ji}}$ are the energetic parameters, and $r_{\mathrm{i}}$ and $q_{\mathrm{i}}$ are the structural parameters corresponding to relative volume and surface area of the component $i$, respectively.

This model has been used for VLE of binary systems containing ILs [65]. The equation has also been used successfully for Liquid-Liquid Equilibria (LLE) of ternary systems including an IL [66,67], and even for Solid-Liquid Equilibria (SLE) of binary systems [68-70]. The main problem using the UNIQUAC model is the need for structural parameters $r_{\mathrm{i}}$ and $q_{\mathrm{i}}$, the volume and surface area of the component. Despite for molecular components these parameters can be obtained easily (even from group-contribution data), in the case of ILs values for both anion and cation are calculated and summed. Different procedures have been proposed $[66,68]$ and used successfully. 
ii.ii In the NRTL model [57], the activity coefficients are calculated as follows:

$$
\ln \gamma_{i}^{N R T L}=\left(\frac{\sum_{j=1}^{n} \tau_{j i} x_{j} G_{j i}}{\sum_{k=1}^{n} x_{k} G_{k i}}\right)+\sum_{j=1}^{n}\left(\frac{x_{j} G_{i j}}{\sum_{k=1}^{n} x_{k} G_{k j}}\right)\left(\tau_{i j}-\frac{\sum_{m=1}^{n} \tau_{m i} x_{m} G_{m i}}{\sum_{k=1}^{n} x_{k} G_{k j}}\right)
$$

where

$$
\begin{gathered}
\mathrm{G}_{\mathrm{ij}}=\exp \left(-\alpha_{\mathrm{ij}} \tau_{\mathrm{ij}}\right) \\
\tau_{i j}=\frac{g_{i j}-g_{j j}}{R T}=\frac{\Delta g_{i j}}{R T} \tau_{j i}=\frac{g_{j i}-g_{i i}}{R T}=\frac{\Delta g_{j i}}{R T}
\end{gathered}
$$

where $x$ represents the mole fraction, $g_{\mathrm{ij}}$ is an energy parameter that characterizes the interaction of species $i$ and $j, R$ is the gas constant, $T$ is the absolute temperature, and the parameter $\alpha_{\mathrm{ij}}=\alpha_{\mathrm{ji}}$ is related to the nonrandomness in the mixture. Although $\alpha_{\mathrm{ij}}$ can be adjusted, it can also be considered fixed in a value, usually between 0.2 and 0.47 .

This is the local composition model most widely used in literature for binary and ternary systems containing ILs, regarding VLE [71-79] with alcohols or water, LLE of binary [80,81] and ternary systems $[67,82-85]$ with ethanol or hydrocarbons or water and also SLE [68-70].

For the explanation of the following models, the Pitzer-Debye-Hückel (PDH) equation [33] has been used as the long-range term on a mole fraction scale as proposed by Chen et al. [86], assuming that the studied mixtures involve completely dissociated electrolytes. For the solvent, the formulation of this equation is:

$$
\ln \gamma_{1}^{\mathrm{PDH}}=\frac{2 A_{\phi} I_{x}^{3 / 2}}{\sqrt{\mathrm{M}_{\mathrm{S}}}\left(1+\rho I_{x}^{1 / 2}\right)}
$$

in which $\rho$ is the number density of ionic species and the term $I$ is the ionic strength on a mole fraction basis, $I=1 / 2 \Sigma x_{\mathrm{i}} z_{\mathrm{i}}^{2}$.

The short-range contribution calculated using different models, such as electrolyte NRTL (eNRTL) [58], non-random factor (NRF) [59], modified NRTL (MNRTL) [60], mean spherical approximation NRTL (MSA-NRTL) [61] or Extended Wilson (EW) [62] are explained below. ii.iii In the e-NRTL model [58], the short-range contribution for the activity coefficient is calculated as: 


$$
\ln \gamma_{1}^{e-N R T L}=2 X_{c}^{2}\left[\frac{2 \tau_{c a, m} \exp \left(-2 \alpha \tau_{c a, m}\right)}{\left(X_{1}+2 X_{c} \exp \left(-\alpha \tau_{c a, m}\right)\right)^{2}}+\frac{\tau_{m, c a} \exp \left(-\alpha \tau_{m, c a}\right)}{\left(X_{1} \exp \left(-\alpha \tau_{m, c a}\right)+X_{C}\right)^{2}}\right]
$$

where $\alpha$ is the nonrandomness factor (usually set to 0.2 ) and $X_{\mathrm{i}}$ is the effective mole fraction of the component $i$, calculated as $X_{\mathrm{i}}=j_{\mathrm{i}} x_{\mathrm{i}}$ with $j_{\mathrm{i}}=z_{\mathrm{i}}$ for ions and $j_{\mathrm{i}}=1$ for solvent. In this model, $\tau_{\mathrm{ca}, \mathrm{m}}$ and $\tau_{\mathrm{m}, \mathrm{ca}}$ are the adjustable parameters.

Examples of the correlation of VLE for binary mixtures [38,73-75] and ternary mixtures [73-75] containing ILs and ethanol or water can be found in literature. Nevertheless, the literature is scarce in examples for SLE [70] and LLE [80,81].

ii.iv The NRF model [59] calculates the short-range contribution for the activity coefficient of the solvent as:

$$
\ln \gamma_{1}^{N R F}=X_{c}\left\{\begin{array}{l}
\left(\frac{v X_{c} \lambda_{E}}{z_{c} v_{c}}\right)\left(1+\frac{\exp \left(-\lambda_{E} / Z\right)}{\left(X_{c} \exp \left(-\lambda_{E} / Z\right)+X_{1}\right)^{2}}\right)- \\
\frac{X_{1} \lambda_{S}\left(\left(v / z_{c} v_{c}\right)-2 \exp \left(-\lambda_{S} / Z\right)\right)}{2 X_{c} \exp \left(-\lambda_{S} / Z\right)+X_{1}} \cdot\left(2-X_{1}\left(1+\frac{1}{2 X_{c} \exp \left(-\lambda_{S} / Z\right)+X_{1}}\right)\right)
\end{array}\right\}
$$

where $v$ and $v_{\mathrm{c}}$ are the total number of ions into which the salt dissociates and the number of cations in one mole of the salt, respectively, and $\mathrm{Z}$ is the coordination number (usually set to 8). In this model $\lambda_{\mathrm{E}}$ and $\lambda_{\mathrm{S}}$ are the adjustable parameters; its use is not common for describing the vapor-liquid equilibria of systems containing ILs [38,77].

ii.v The short-range contribution in the MNRTL model has been developed by Jaretum and Aly [60], and Sardroodi et al. [87] used it in the presented form for the first time:

$$
\ln \gamma_{1}{ }^{M N R T L}=4 X_{c}{ }^{2}\left[\tau_{c a, m} W_{c a, m} /\left(X_{1}+2 W_{c a, m} X_{c}\right)^{2}+\tau_{m, c a}\left(W_{m, c a}-1\right) /\left(X_{c}+X_{1} W_{c a, m}\right)^{2}\right]
$$

where $\tau_{\mathrm{ca}, \mathrm{m}}$ and $\tau_{\mathrm{m}, \mathrm{ca}}$ are the parameters of the model, $X_{\mathrm{i}}$ is the effective mole fraction, and the next expression is assumed:

$$
W_{i}=\exp \left(-\alpha \tau_{i}+w_{i}\right)
$$

where $\alpha$ is the nonrandomness factor (usually fixed to 0.2 ) and $\omega_{\mathrm{ca}, \mathrm{m}}$ and $\omega_{\mathrm{m}, \mathrm{ca}}$ are the adjustable parameters.

Among the local composition models, it is one of those giving lower deviations for the modeling of VLE of systems with ILs [34-37,47-54,77]. 
ii.vi The equation for calculating the short-range contribution for the activity coefficient of the solvent given by the MSA-NRTL model [61] is as follows:

$$
\ln \gamma_{1}^{M S A-N R T L}=\frac{A}{B^{2}}+v_{c} v_{a}\left(C_{C}+C_{a}\right)+v \tau_{m c, a c}^{2} x_{S}^{2} x_{S}^{i}\left(D_{C}+D_{a}\right)
$$

taking into account that:

$$
\begin{gathered}
A=\left(v_{c} p_{c m} \tau_{c m}+v_{a} p_{a m} \tau_{a m}\right)\left(v_{c} p_{c m}+v_{a} p_{a m}\right) \\
B=v_{c} p_{c m}+v_{a} p_{a m}+x_{S}^{1} \\
C_{c}=p_{c m, a c} \tau_{m c, a c} /\left(v_{a}+x_{S}^{i} p_{m c, a c}\right)^{2} \\
C_{a}=p_{m a, c a} \tau_{m a, c a} /\left(v_{c}+x_{S}^{i} p_{m a, c a}\right)^{2} \\
D_{c}=\frac{v_{c} p_{m c, a c}}{\left(v_{a}+x_{S}^{i} p_{m c, a c}\right)^{2}\left(1-\frac{v_{a} \alpha \tau_{m c, a c}}{v_{a}+x_{S}^{i} p_{m c, a c}}\right)} \\
D_{a}=\frac{v_{a} p_{m a, c a}}{\left(v_{c}+x_{S}^{i} p_{m a, c a}\right)^{2}\left(1-\frac{v_{c} \alpha \tau_{m a, c a}}{v_{c}+x_{S}^{i} p_{m a, c a}}\right)}
\end{gathered}
$$

being

$$
\begin{gathered}
\mathrm{p}_{\mathrm{i}}=\exp \left(-\alpha \tau_{\mathrm{i}}\right) \\
\tau_{\mathrm{ma}, \mathrm{ca}}=\tau_{\mathrm{mc}, \mathrm{ac}}+\tau_{\mathrm{am}}-\tau_{\mathrm{cm}} \\
\tau_{\mathrm{mc}, \mathrm{ac}}=\tau_{\mathrm{mc}, \mathrm{ac}}^{1}+\tau_{\mathrm{mc}, \mathrm{ac}}^{2} X_{1} \\
x^{i}=x_{1} / x_{S}=1 / x_{S}-v
\end{gathered}
$$


in which $x_{1}$ and $x_{\mathrm{S}}$ are the mole fraction of solvent and salt, respectively.

The correlation using this model it is not common for the treatment of the VLE data of systems containing ILs [77].

ii.vii The EW model was presented by Zhao et al. [62], and it describes the short-range contribution for the activity coefficient as:

$$
\begin{aligned}
& \ln \gamma_{1}^{E W}=-C\left(\ln \left(\frac{X_{1}+2 X_{c} \exp \left(-E_{e 1} / C R T\right)}{X_{1}+2 X_{c}}\right)\right)+ \\
& 2 X_{c}\left(\frac{\left(1-\exp \left(-E_{e 1} / C R T\right)\right) X_{1}}{\left(X_{1}+2 X_{c} \exp \left(-E_{e 1} / C R T\right)\right)\left(X_{1}+2 X_{c}\right)}+\frac{X_{c}\left(\exp \left(-E_{1 e} / C R T\right)-1\right)}{\left(X_{1} \exp \left(-E_{1 e} / C R T\right)+X_{c}\right)\left(X_{1}+X_{c}\right)}\right)
\end{aligned}
$$

where $C$ is the coordination number (set to 10 [77]). In this model, $E_{\mathrm{e} 1}$ and $E_{1 \mathrm{e}}$ are the adjustable parameters. This model has been checked for its use in VLE of aqueous systems with ILs [77].

\begin{tabular}{lccc}
\hline \multirow{2}{*}{ Model } & \multicolumn{3}{c}{ References } \\
\cline { 2 - 4 } & VLE & LLE & SLE \\
\hline Pitzer & {$[34-38]$} & & \\
\hline Extended Pitzer of Archer & {$[46-55]$} & {$[66,67]$} & {$[68-70]$} \\
\hline UNIQUAC & {$[65]$} & {$[67,80-85]$} & {$[70-72]$} \\
\hline NRTL & {$[71-79]$} & {$[80,81]$} & \\
\hline e-NRTL & {$[38,73-75]$} & & \\
\hline NRF & {$[38,77]$} & & \\
\hline MNRTL & {$[34-37,47-54,77]$} & & \\
\hline MSA-NRTL & {$[77]$} & {$[77]$} & \\
\hline EW & & & \\
\hline
\end{tabular}

Table 1. Literature examples for the modeling of phase equilibria in systems containing ILs

A list of representative examples found in literature for the modeling of phase equilibria in systems containing ILs with the above mentioned models is presented in Table 1.

Among these correlation models, those which have demonstrated to give the best results in VLE are the Extended Pitzer model of Archer, the NRTL and the MNRTL models. Regarding LLE and SLE, there are less examples available, specially comparing different models. Nevertheless, it is clear that NRTL is, by far, the most used equation. It is also important to highlight that differences in performance among the models are small. 


\subsection{Equations of state}

Equations of state (EoS) are powerful tools, which can be used to describe the properties of pure fluids or their mixtures. In the last 10 years, this kind of models has been widely applied to describe the properties of pure ILs, as well as to model the phase equilibrium (VLE and LLE) of mixtures containing them.

\subsubsection{Peng-Robinson}

The Peng-Robinson EoS was developed in 1976 by Peng and Robinson [88] and can be expressed as:

$$
P=\frac{R T}{V-b}-\frac{a}{V(V+b)+b(V-b)}
$$

with:

$$
\begin{gathered}
b=0.077796 \frac{R T_{c}}{P_{c}} \\
a=0.457235 \frac{R^{2} T_{c}^{2}}{P_{c}} \alpha \\
\alpha=\left[1+m\left(1-\sqrt{\frac{T}{T_{c}}}\right)\right]^{2} \\
m=0.37464+1.54226 \omega-0.26992 \omega^{2}
\end{gathered}
$$

where $T_{c}$ is the critical temperature, $P_{c}$ is the critical pressure and $\omega$ is the acentric factor. For most ILs, the critical properties and the acentric factor are impossible to determine experimentally, because they start to decompose even before the temperature reaches the boiling point. For this reason, Valderrama and co-workers have applied an extended group contribution method, the modified Lydersen-Joback-Reid method, to determine the critical properties, boiling temperatures and acentric factors of several ILs [89-92]. This method only requires knowledge of the structure of the ILs and its molecular weight. Since there are no experimental data available for these properties, the accuracy of the method is verified by comparing calculated liquid densities of the ILs to experimental data available. The results show that the method is sufficiently accurate for several applications, with average absolute deviations (AAD) between calculated and experimental liquid densities in the range of 5 to $6 \%$. The properties determined by this research group have been widely used by the scientific community when modeling the properties of ILs and its mixtures, using this or other equations.

For mixtures of fluids, mixing rules have to be applied to parameters $a$ and $b$, which imply the use of one or more binary interaction parameters. For systems containing ILs, the Wong- 
Sandler mixing rules have been widely used [93-96], as well as the quadratic [97,98], van der Waals [94], [99,100] and Mathias-Klots-Prausnitz mixing rules [101,102].

The application of the Peng-Robinson EoS to systems with ILs has been mainly focusing on the VLE with $\mathrm{CO}_{2}$ and other gases. For example, Shin et al. [103] modeled the high-pressure solubilities of $\mathrm{CO}_{2}$ in ILs of the family $\left[\mathrm{C}_{\mathrm{n}} \operatorname{mim}\right]\left[\mathrm{Tf}_{2} \mathrm{~N}\right]$ (1-alkyl-3-methylimidazolium bis(trifluoromethylsulfonyl) imide) using this EoS and quadratic mixing rules with two temperature-dependent binary interaction parameters. They obtained AAD between calculated and experimental equilibrium pressures between 10 and 14\%, for which they conclude that the model can satisfactorily predict the solubility of high-pressure $\mathrm{CO}_{2}$ in this family of ILs over a wide range of pressures up to the supercritical region of $\mathrm{CO}_{2}$. Also Álvarez and Aznar [93] used the Peng-Robinson EoS to model the VLE of binary systems composed of IL + supercritical $\mathrm{CO}_{2}$ or $\mathrm{CHF}_{3}$ and IL + hydrocarbons. In this work, the van der Waals and Wong-Sandler mixing rules were used, with UNIQUAC and NRTL models used as excess Gibbs energy models in the Wong-Sandler mixing rules. Their results present AAD in pressure between 2 and $24 \%$ for low pressures and between 7 and 52\% for high pressures. The authors conclude that the EoS is not able to represent the data at high pressures; however, it performs well at low pressures. Later, Álvarez et al. [104] used the Peng-Robinson EoS with the Wong-Sandler mixing rules, once again with UNIQUAC and NRTL models for the excess Gibbs energy, but also using the COSMO-SAC model. They modeled the isobaric VLE of 1ethyl-3-methylimidazolium ethylsulfate $\left(\left[\mathrm{C}_{2} \mathrm{mim}\right]\left[\mathrm{EtSO}_{4}\right]\right)$ with propionaldehyde or valeraldehyde. When using UNIQUAC or NRTL models, they obtain AAD below $0.15 \%$ for both systems. Since the COSMO-SAC model is a predictive model, i.e., it does not require any adjustable binary interaction parameters, the authors regard the application of this model with the Peng-Robinson EoS and the Wong-Sandler mixing rules as pure predictive results. The AAD obtained in this way was 0.3 and $2 \%$ for each system, respectively. As a final example, Ren and Scurto [99] used the Peng-Robinson EoS with the van der Waals one fluid mixing rule to model the VLE and VLLE of imidazolium-based ILs and the refrigerant gas 1,1,1,2tetrafluoroethane. The authors obtained AAD values between 0.4 and $7.4 \%$ for VLE and concluded that the model is able to represent the bubble-point data with excellent agreement. However, when using the interaction parameters regressed from the VLE data alone to predict compositions of the VLLE transition to LLE, only satisfactory results were obtained for all systems.

\subsubsection{Soave-Redlich-Kwong}

A Soave modification of the Redlich-Kwong EoS [105] has been frequently applied to systems with ILs. The Soave-Redlich-Kwogn (SRK) EoS was introduced in 1972 by Giorgio Soave, and can be expressed as:

$$
P=\frac{R T}{V-b}-\frac{a(T)}{V(V+b)}
$$

with: 


$$
\begin{gathered}
a(T)=0.427480 \frac{R^{2} T_{c}{ }^{2}}{P_{c}} \alpha(T) \\
b=0.08664 \frac{R T_{c}}{P_{c}}
\end{gathered}
$$

In the works involving systems with ILs, the temperature dependent part of the $a$ parameter has been modeled by the empirical form:

$$
\alpha(T)=\sum_{k=0}^{\leq 3} \beta_{k}\left(\frac{T_{c}}{T}-\frac{T}{T_{c}}\right)^{k}
$$

Coefficients $\beta_{\kappa}$ are usually determined to reproduce the vapor pressure of the pure compound. However, since there are no available experimental vapor pressure data for most ILs, the coefficients are treated as adjustable fitting parameters in the calculations [106]. The authors have found that for ILs, only one adjustable parameter, $\beta_{1}$, is sufficient (with $\beta_{0}=1$ and $\beta_{2}=\beta_{3}=0$ ). In the case of this EoS, modified van der Waals-Berthelot mixing rules have been used, with four binary interaction parameters.

Shiflett and Yokozeki [106] first used this EoS to correlate the solubility of $\mathrm{CO}_{2}$ in ILs l-butyl-3-methylimidazolium hexafluorophosphate $\left(\left[\mathrm{C}_{4} \mathrm{mim}\right]\left[\mathrm{PF}_{6}\right]\right)$ and 1-butyl-3-methylimidazolium tetrafluoroborate $\left(\left[\mathrm{C}_{4} \mathrm{mim}\right]\left[\mathrm{BF}_{4}\right]\right)$. The authors obtained an excellent fit between experimental and calculated solubility data, with standard deviations of 17 and $10.5 \mathrm{kPa}$ for each system, respectively. They used the same model to correlate the VLE of $\mathrm{CO}_{2}$ and other gases (like ammonia $[107,108]$ or $\mathrm{SO}_{2}[109]$ ) in different ILs. Later, the same authors modeled the solubility of water in several different ILs using the same EoS [110]. The four binary interaction parameters were determined using binary VLE data from the literature, having obtained standard deviations lower than $0.6 \mathrm{kPa}$ for all systems. The graphical results presented by the authors show a very good agreement between experimental and calculated solubilities of water in all ILs considered. The same research group has also used the SRK EoS to study the phase behavior of ternary mixtures $\mathrm{CO}_{2} / \mathrm{H}_{2} /\left[\mathrm{C}_{4} \mathrm{mim}\right]\left[\mathrm{PF}_{6}\right][111], \mathrm{CO}_{2} / \mathrm{SO}_{2} / 1-$ butyl-3-methylimidazolium methyl sulfate ([C $\left.\left.\mathrm{C}_{4} \mathrm{mim}\right][\mathrm{MeSO}]\right)$ [112], $\mathrm{CO}_{2} / \mathrm{H}_{2} \mathrm{~S} /\left[\mathrm{C}_{4} \mathrm{mim}\right]\left[\mathrm{PF}_{6}\right]$ [113] and $\mathrm{CO}_{2} / \mathrm{H}_{2} \mathrm{~S} /\left[\mathrm{C}_{4} \mathrm{mim}\right]\left[\mathrm{MeSO}_{4}\right]$ [114]. For all the previous studies the authors obtained good agreement between calculated and experimental data. Very recently, Shiflett et al. [115] have also modeled the ternary system $\mathrm{N}_{2} \mathrm{O} / \mathrm{CO}_{2} / 1$-butyl-3-methylimidazolium acetate ([C $\left.\mathrm{C}_{4} \mathrm{mim}\right][\mathrm{Ac}]$ ) with the purpose of understanding the separation of $\mathrm{N}_{2} \mathrm{O}$ and $\mathrm{CO}_{2}$ using ILs. They determined the binary interaction parameters using VLE data (either their own or from the literature) for the pairs $\mathrm{N}_{2} \mathrm{O} /\left[\mathrm{C}_{4} \mathrm{mim}\right][\mathrm{Ac}], \mathrm{CO}_{2} /\left[\mathrm{C}_{4} \mathrm{mim}\right][\mathrm{Ac}]$ and $\mathrm{N}_{2} \mathrm{O} / \mathrm{CO}_{2}$. Unlike what happened in the previously mentioned ternary systems, the phase behavior prediction of the ternary system of $\mathrm{N}_{2} \mathrm{O} / \mathrm{CO}_{2} /\left[\mathrm{C}_{4} \mathrm{mim}\right][\mathrm{Ac}]$ may not be guaranteed based on the binary interaction parameters alone. This happens because for systems containing mixtures with the chemical complex formation (hydrogen-bonding, charge-transfer complex, etc.) as in the case of the binary $\mathrm{CO}_{2} /\left[\mathrm{C}_{4} \mathrm{mim}\right][\mathrm{Ac}]$ here present, the third component (in this case, $\mathrm{N}_{2} \mathrm{O}$ ) may interfere with the binary interactions of $\mathrm{CO}_{2} /\left[\mathrm{C}_{4} \mathrm{mim}\right][\mathrm{Ac}]$, originating a decrease or an 
increase of the complex formation and changing the binary interaction parameters of this pair in the ternary system. Consequently, one of the binary interaction parameters of the pair $\mathrm{CO}_{2} /\left[\mathrm{C}_{4} \mathrm{mim}\right][\mathrm{Ac}]$ was modified so as to fit the experimental ternary VLE data. This way, the model provides an excellent agreement between experimental and calculated data for the ternary system.

\subsubsection{Statistical associating fluid theory}

The original Statistical Associating Fluid Theory (SAFT) was developed in 1989 [116] based on Wertheim's first-order thermodynamic perturbation theory [117-120]. Its main advantage over the traditional cubic EoS, is that it takes into account the structure of the molecule, similarly to group contribution models. It regards the molecules as chains of hard-spheres, which contain multiple association sites. Several variations of the SAFT EoS have been used to model the phase behavior of systems containing ILs: tPC-PSAFT [121-125], soft-SAFT [126-128], hetero-SAFT [129], PCP-SAFT [130] and PC-SAFT [131].

Kroon et al. [121] applied the tPC-PSAFT model to the phase behavior of IL $+\mathrm{CO}_{2}$ systems and later Karakatsani et al. [122] applied it to the correlation of the solubility of $\mathrm{CO}_{2}, \mathrm{CO}, \mathrm{O}_{2}$ and $\mathrm{CHF}_{3}$ in the same ILs. Pure component parameters for the ILs were estimated from ILs experimental thermodynamic data (density, enthalpy, and entropy of dissolution of $\mathrm{CO}_{2}$ ) and physicochemical data for the constituent ions (size, polarizability, number of electrons). The cross-association parameters were estimated from enthalpy and entropy data for the dissolution of $\mathrm{CO}_{2}$ in the ILs. A temperature-dependent binary interaction parameter $k_{i j}$ was adjusted in order to fit the model to experimental VLE data. The results of the model were in good agreement with experimental data. Later, Karakatsani and Economou [123] used the same parameters to model the VLE of the ternary system $\mathrm{CO}_{2} /$ acetone/[ $\left.\mathrm{C}_{4} \mathrm{mim}\right]\left[\mathrm{PF}_{6}\right]$, also obtaining satisfactory agreement between calculated and experimental data. Additionally, Economou et al. [124] applied the same model to describe the VLE of the binary $\left[\mathrm{C}_{8} \mathrm{mim}\right]$ $\left[\mathrm{BF}_{4}\right] /$ benzene and the ternary $\mathrm{CO}_{2} / \mathrm{H}_{2} \mathrm{O} /\left[\mathrm{C}_{4}\right.$ mim $]\left[\mathrm{NO}_{3}\right]$ (1-butyl-3-methylimidazolium nitrate) systems. For binary mixture calculations, a binary interaction parameter was fitted to the experimental data and the model was capable of accurately correlating the phase equilibria of the binary and of the ternary IL mixtures with polar solvents. In a more recent work, Karakatsani et al. [125] proved that the model can accurately predict the phase equilibrium of non-polar solvent/IL mixtures, without the use of any adjustable binary interaction parameter, by applying it to binary and ternary mixtures of ILs with organic solvents and water. They also concluded that in the case of aqueous solvents, the dissociation of IL has to be incorporated explicitly into the model in order to obtain a good correlation with the experimental data.

Andreu and Vega [126] used the soft-SAFT EoS to describe the solubility of $\mathrm{CO}_{2}$ in ILs. They modeled the families of ILs $\left[\mathrm{C}_{n} \mathrm{mim}\right]\left[\mathrm{BF}_{4}\right]$ and $\left[\mathrm{C}_{n} \mathrm{mim}\right]\left[\mathrm{PF}_{6}\right]$ as Lennard-Jones chains with one associating site in each molecule. The chain length, size and energy parameters of the ILs were obtained by fitting the model predictions to available density data, obtaining AAD values lower than $0.2 \%$. For the association parameters of ILs, values previously used for alkanols were adopted. The authors found that the model correlations and experimental data 
for VLE are in good agreement. They later used the same model to describe the solubility of hydrogen, $\mathrm{CO}_{2}$ and xenon in ILs of the family $\left[\mathrm{C}_{\mathrm{n}} \mathrm{mim}\right]\left[\mathrm{Tf}_{2} \mathrm{~N}\right]$ [127]. In this case, the ILs were modeled as Lennard-Jones chains with three associating sites in each molecule. The pure component parameters for ILs were obtained as in the previous work, and a good description of experimental solubilities was obtained. Recently, Llovell et al. [128] re-parameterized the model for the $\left[\mathrm{C}_{\mathrm{n}} \operatorname{mim}\right]\left[\mathrm{Tf}_{2} \mathrm{~N}\right]$ family of ILs and modeled the solubilities of methanol and ethanol. Good agreement was found between the predictions of the model and the experimental data, with AAD values below $5 \%$ for methanol and around $10 \%$ for ethanol. They also modeled the VLE of IL/water systems, with the model providing good agreement with the experimental data, with AAD values between 6 and 12\%. As for the LLE of mixtures of ILs with water, the authors were not able to obtain reasonable predictions, having obtained significant deviations in the water-rich phase. Quantitative agreement was achieved by using two adjustable parameters, which were adjusted only to the water-rich phase of the aqueous $\left[\mathrm{C}_{4} \mathrm{mim}\right]\left[\mathrm{Tf}_{2} \mathrm{~N}\right]$ mixture and used in a predictive manner for the IL-rich phase and for the aqueous mixtures with $\left[\mathrm{C}_{2} \operatorname{mim}\right]\left[\mathrm{Tf}_{2} \mathrm{~N}\right]$ and $\left[\mathrm{C}_{6} \operatorname{mim}\right]\left[\mathrm{Tf}_{2} \mathrm{~N}\right]$.

Ji and Adidharma [129] used the heterosegmented SAFT (hetero-SAFT) to describe the solubility of $\mathrm{CO}_{2}$ in the families of ILs $\left[\mathrm{C}_{n} \mathrm{mim}\right]\left[\mathrm{BF}_{4}\right],\left[\mathrm{C}_{n} \mathrm{mim}\right]\left[\mathrm{PF}_{6}\right]$ and $\left[\mathrm{C}_{n} \mathrm{mim}\right]\left[\mathrm{Tf} \mathrm{f}_{2} \mathrm{~N}\right]$. The molecules of ILs were divided into groups representing the alkyl chain, the cation head and the anion. To account for the electrostatic/polar interactions between cation and anion, the spherical segments representing the cation head and the anion were assumed to have one association site each, which can only associate to each other. The parameters for the alkyl chains were obtained from those of the corresponding n-alkanes and the parameters for groups representing the cation head and the anion, including the two association parameters, were fitted to experimental IL density data. The model was capable of satisfactorily describing the solubility of $\mathrm{CO}_{2}$ in the ILs studied.

Finally, Paduszynski et al. [130] used the Perturbed-Chain Polar Statistical Associating Fluid Theory (PCP-SAFT) to model the LLE of the IL 1-methyl-1-propylpiperidinium bis(trifluoromethylsulfonyl)imide $\left[\mathrm{C}_{3}\right.$ mpip] $\left[\mathrm{NTf}_{2}\right]$ with several alkan-1-ols. They modeled the IL as strongly associating molecules, with symbol $\mathrm{A}_{1}$ representing a positive site which corresponds to the nitrogen atom on the cation and its proximity, and symbol $\mathrm{B}_{1}$ representing a negative site which corresponds to the delocalized charge due to the oxygen molecules on the anion. They defined each type of associating site in an identical way; however, they only allowed $A_{1} B_{1}$ interactions to take place. Additionally, they assumed that each molecule has 5 positive sites of type $A_{1}$ and 5 negative sites of type $B_{1}$. The pure component parameters of the IL were determined by fitting to liquid density and total solubility parameter data. Selfassociation of IL and alkan-1-ols, as well as cross-association, were accounted for and one linearly temperature-dependent binary interaction parameter was needed in order to obtain qualitative agreement between calculated and experimental data. AAD values obtained were between 0.6 and 5\%. On a different work, Paduszynski and Domanska [131] modeled the LLE of systems composed by piperidinium-based ILs $\left(\left[\mathrm{C}_{3}\right.\right.$ mpip] $\left[\mathrm{NTf}_{2}\right]$ and $\left[\mathrm{C}_{4} \mathrm{mpip}\right]$ $\left.\left[\mathrm{NTf}_{2}\right]\right)$ and several aliphatic hydrocarbons using the Perturbed-Chain Statistical Associating Fluid Theory (PC-SAFT) model. Pure component parameters for ILs were obtained as in the 
previous work and they used activity coefficients at infinite dilution of hydrocarbons in ILs reported in the literature to optimize the binary interaction parameter, which was again considered to be linearly temperature-dependent, with two adjustable parameters. In the calculation of the LLE of the systems, they obtained AAD values between 1.5 and $8 \%$. Additionally, the authors decided to test their approach for the cross-associating systems $\left[\mathrm{C}_{3}\right.$ mpip $]\left[\mathrm{NTf}_{2}\right]+1$-pentanol and $\left[\mathrm{C}_{3}\right.$ mpip $]\left[\mathrm{NTf}_{2}\right]+$ water. Regarding the LLE of $\left[\mathrm{C}_{3} \mathrm{mpip}\right]$ $\left[\mathrm{NTf}_{2}\right]+1$-pentanol, the authors claim that the experimental data is well described by the model, although deviations between calculated and experimental compositions increase as the temperature increases and the model ends up over predicting the upper critical solution temperature by about $15 \mathrm{~K}$. The AAD values obtained for this system were $52 \%$ for the ILrich phase and $1.7 \%$ for the alcohol-rich phase. As for the system $\left[\mathrm{C}_{3} \mathrm{mpip}\right]\left[\mathrm{NTf}_{2}\right]+$ water, the authors conclude that the PC-SAFT model is surprisingly good at describing the experimental data, but only when the IL-rich phase is considered alone. For the water-rich phase, the model predicts solubilities of IL much lower than those observed experimentally by several orders of magnitude. The authors justify this fact because the molecular model chosen for the IL is not appropriate for dilute solutions of IL in water, in which case the cation and anion of the IL are probably dissociated, which results on increased solubility.

\subsubsection{Other EoS}

Several other EoS have been used to model systems with ILs. For example, Tsioptsias et al. [132] used the Non-Random Hydrogen-Bonding (NRHB) model [133] to describe the phase behavior of binary systems containing ILs of the family $\left[\mathrm{C}_{n} \operatorname{mim}\right]\left[\mathrm{Tf}_{2} \mathrm{~N}\right]$, obtaining good agreement between model correlations and experimental data. Wang et al. [134] used the square well chain fluid (SWCF) EoS [135] to model the solubilities of gases such as $\mathrm{CO}_{2}$, $\mathrm{C}_{3} \mathrm{H}_{6}, \mathrm{C}_{3} \mathrm{H}_{8}$ and $\mathrm{C}_{4} \mathrm{H}_{10}$ in several ILs. Breure et al. [136] used a group contribution EoS to study the phase behavior of binary systems of ILs of the families $\left[\mathrm{C}_{n} \mathrm{mim}\right]\left[\mathrm{PF}_{6}\right]$ and $\left[\mathrm{C}_{n} \mathrm{mim}\right]$ $\left[\mathrm{BF}_{4}\right]$ with $\mathrm{CO}_{2}$, also obtaining good agreement between model predictions and experimental data. Very recently, Maia et al. [137] applied the Cubic Plus Association (CPA) EoS [138], which combines the SRK EoS with an advanced association term similar to that of the SAFT type models, to describe the VLE with $\mathrm{CO}_{2}$ and the LLE with water of ILs $\left[\mathrm{C}_{2} \operatorname{mim}\right]\left[\mathrm{Tf}_{2} \mathrm{~N}\right]$ and $\left[\mathrm{C}_{4} \mathrm{mim}\right]\left[\mathrm{Tf}_{2} \mathrm{~N}\right]$. Good agreement was obtained between calculated and experimental data, even though smaller AAD percentage values were obtained for the VLE than for the LLE.

\section{Conclusions}

Regarding the treatment of physical properties of pure ILs, temperature dependence of physical properties such as density, speed of sound, or refractive index is described using simple polynomial expressions, mainly equations of first, second and third order. For the viscosity, usually the VFT or mVFT equations are strongly recommended. For binary mixtures containing ILs, the dependence of the physical properties with temperature and composition is also correlated using empirical equations, and their excess properties are 
generally fitted to a Redlich-Kister type equation. For the fitting of the excess properties of ternary systems containing ILs, the most widely used equation is that proposed by Cibulka.

For the correlation of experimental data concerning phase equilibria of mixtures containing ILs, several $\mathrm{g}^{\mathrm{E}}$-based models have been applied in literature (Pitzer, Extended Pitzer model of Archer, UNIQUAC, NRTL, e-NRTL, NRF, MNRTL, MSA-NRTL, EW), being the NRTL model the one that unifies simplicity and satisfactory results for the treatment of vapor-liquid, liquid-liquid and solid-liquid equilibria.

The use of EoS for the modeling of phase equilibria involving ILs is frequent. Unlike what happens with $\mathrm{g}^{\mathrm{E}}$ models, most of the literature with EoS involve VLE data, rather than LLE or SLE. Nevertheless, many authors have proved that excellent results can be obtained in data correlation or, for some cases, even prediction. The main difficulty with the application of EoS is the calculation of pure component parameters for ILs. Up to date, a general procedure has not yet been defined. Very recently, a complete review on the use of EoS with ILs, with special emphasis on the obtention of model parameters, has been published by Maia and co-workers [137]. The interested reader is directed to that work for further details.

\section{Author details}

Filipa M. Maia, Noelia Calvar, Emilio J. González, Aristides P. Carneiro, Oscar Rodriguez and Eugénia A. Macedo

LSRE-Laboratory of Separation and Reaction Engineering, Associate Laboratory LSRE/LCM, Department of Chemical Engineering, Faculty of Engineering, University of Porto, Rua Dr. Roberto Frias, Porto, Portugal

\section{References}

[1] Short PL. Out of the ivory tower. Chemical and Engineering News 2006;84(17) 15-21.

[2] Aparicio S, Atilhan M, Karadas F. thermophysical properties of pure ionic liquids: review of present situation. Industial and Engineering Chemistry Research. 2010;49(20) 9580-9595.

[3] Tariq M, Forte PAS, Gomes MFC, Lopes JNC, Rebelo LPN. Densities and refractive indices of imidazolium and phosphonium based ionic liquids: effect of temperature, alkyl chain length, and anion. Journal of Chemical Thermodynamics. 2009;41(6) 790-798.

[4] Widegren JA, Magee JW. Density, viscosity, speed of sound, and electrolytic conductivity for the ionic liquid 1-hexyl-3-methylimidazolium bis(trifluoromethylsulfonyl)imide and its mixtures with water. Journal Chemical and Engineering Data 2007;52(6) 2331-2338. 
[5] Seoane RG, Corderí S, Gómez E, Calvar N, Gonzalez EJ, Macedo EA, Domínguez A. Temperature dependence and structural influence on the thermophysical properties of eleven commercial ionic liquids. Industrial and Engineering Chemical Research 2012;51(5) 2492-2504.

[6] Gu Z, Brennecke JF. Volume expansivities and isothermal compressibilities of imidazolium and pyridinium-based ionic liquids. Journal Chemical and Engineering Data 2002;47(2) 339-345.

[7] Paduszyn'ski K, Doman'ska U, Chang H. Thermodynamic modeling of ionic liquid systems: development and detailed overview of novel methodology based on the PC-SAFT. Journal of Physical Chemistry B - Condensed Phase 2012;116(16) 5002-5018.

[8] Tome LIN, Gardas RL, Carvalho PJ, Pastoriza-Gallego MJ, Piñeiro MM, Coutinho JAP. Measurements and correlation of high-pressure densities of phosphonium based ionic liquids. Journal Chemical and Engineering Data 2011;56(5) 2205-2217.

[9] Machida H, Sato Y, Smith RL. Pressure-volume-temperature (PVT) measurements of ionic liquids $\left(\left[\mathrm{bmim}^{+}\right]\left[\mathrm{PF}^{-}\right]\right.$, , $\left.\left.\mathrm{bmim}^{+}\right][\mathrm{BF} 4-],[\mathrm{bmim}+][\mathrm{OcSO} 4-]\right)$ and analysis with the Sanchez-Lacombe equation of state. Fluid Phase Equilibria 2008;264(1-2) 147-155.

[10] Dymond JH, Malhotra R. The Tait equation: 100 years on. International Journal of Thermophysics 1988;9(6) 941-951.

[11] Harris KR, Kanakubo M, Woolf LA. Temperature and pressure dependence of the viscosity of the ionic liquids 1-methyl-3-octylimidazolium hexafluorophosphate and 1-methyl-3-octylimidazolium tetrafluoroborate. Journal Chemical and Engineering Data 2006;51(3) 1161-1167.

[12] Tomida D, Kumagai A, Kenmochi S, Qiao K, Yokoyama C. Viscosity of 1-hexyl-3methylimidazolium hexafluorophosphate and 1-octyl-3-methylimidazolium hexafluorophosphate at high pressure. Journal Chemical and Engineering Data 2007;52(2) 577-579.

[13] Bandres I, Alcalde R, Lafuente C, Atilhan M, Aparicio S. On the viscosity of pyridinium based ionic liquids: an experimental and computational study. Journal of Physical Chemistry B 2011;115(43) 12499-12513.

[14] Ahosseini A, Scurto AM. Viscosity of imidazolium-based ionic liquids at elevated pressures: cation and anion effects. International Journal of Thermophysics 2008;29(4) 1222-1243.

[15] Seddon KR, Starck AS, Torres, MJ. ACS Symposium Series 901: Washington DC, 2004.

[16] Vogel H. The law of the relation between the viscosity of liquids and the temperature. Phys. Z. 1921;22, 645-646. 
[17] Fulcher GS. Analysis of recent measurements of the viscosity of glasses. Journal of the American Ceramic Society 1925;8(6) 339-355.

[18] Tammann G, Hesse W. The dependence of viscosity upon the temperature of supercooled liquids. Zeitschrift für anorganische und allgemeine Chemie 1926;156(1) 245-257.

[19] Litovitz, TA. Temperature dependence of the viscosity of associated liquids. Journal of Chemical Physics 1952;20(7) 1088-1089.

[20] Geppert-Rybczyn'ska M, Heintz A, Lehmann JK, Golus A. Volumetric properties of binary mixtures containing ionic liquids and some aprotic solvents. Journal Chemical and Engineering Data 2010;55(9) 4114-4120.

[21] Heintz A, Klasen D, Lehmann JK, Wertz C. Excess molar volumes and liquid-liquid equilibria of the ionic liquid 1-methyl-3-octyl-imidazolium tetrafluoroborate mixed with butan-1-ol and pentan-1-ol. Journal of Solution Chemistry 2005;34(10) 11351144 .

[22] Vercher E, Llopis FJ, González-Alfaro MV, Martínez-Andreu A. Density, speed of sound, and refractive index of 1-ethyl-3-methylimidazolium triiifluoromethanesulfonate with acetone, methyl acetate, and ethyl acetate at temperatures from (278.15 to 328.15) K. Journal Chemical and Engineering Data 2010;55 (3) 1377-1388.

[23] González EJ, Domínguez A, Macedo EA. Excess properties of binary mixtures containing 1-hexyl-3-methylimidazoliumbis(trifluoromethylsulfonyl)imide ionic liquid and polar organic compounds. Journal of Chemical Thermodynamics 2012;47(1) 300-311.

[24] García-Miaja G, Troncoso J, Romaní L. Excess enthalpy, density, and heat capacity for binary systems of alkylimidazolium-based ionic liquids + water. Journal of Chemical Thermodynamics 2009;41(2) 161-166.

[25] Connors KA, Wright JL. Dependence of surface tension on composition of binary aqueous-organic solutions. Analytical Chemistry 1989;61(3) 194-198.

[26] Redlich O, Kister AT. Algebraic representation of thermodynamic properties and the classification of solutions. Industrial and Engineering Chemistry 1948;40(2) 345-348.

[27] González B, Calvar N, González E, Domínguez A. Density and viscosity experimental data of the ternary mixtures 1-propanol or 2-propanol + water + 1-ethyl-3-methylimidazolium ethylsulfate. Correlation and prediction of physical properties of the ternary systems. Journal of Chemical and Engineering Data 2008;53(3) 881-887.

[28] Gómez E, González B, Calvar N, Domínguez A. Excess molar properties of ternary system (ethanol + water + 1,3-dimethylimidazolium methylsulphate) and its binary mixtures at several temperatures. Journal of Chemical Thermodynamics 2008;40(8) 1208-1216.

[29] Andreatta AE, Arce A, Rodil E, Soto A. Physico-chemical properties of binary and ternary mixtures of ethyl acetate + ethanol +1-butyl-3-methyl-imidazolium bis(tri- 
fluoromethylsulfonyl)imide at $298.15 \mathrm{~K}$ an atmospheric pressure. Journal of Solution Chemistry 2010;39(3) 371-383.

[30] Cibulka I. Estimation of excess volume and density of ternary liquid mixtures of nonelectrolytes from binary data. Collection of Czechoslovak Chemical Communication 1982;47(5) 1414-1419.

[31] Singh P, Nigam R, Sharma S, Aggarwal S. Molar excess volumes of ternary mixtures of nonelectrolytes. Fluid Phase Equilibria 1984;18(3) 333-344.

[32] Nagata M, Sakura J. Refractive index and excess volume for binary liquid mixtures. Part 1. Analyses of new and old data for binary mixtures. Journal of the Chemical Society, Faraday Transactions 1 1987;83(8) 2449-2457.

[33] Pitzer KS. Activity Coefficients in Electrolyte Solutions. Ed. CRC Press: Boca Raton, FL; 1991.

[34] Shekaari H, Mousavi SS. Influence of alkyl chain on the thermodynamic properties of aqueous solutions of ionic liquids 1-alkyl-3-methylimidazolium bromide at different temperatures. The Journal of Chemical Thermodynamics 2009;41 90-96.

[35] Shekaari H, Mousavi SS, Mansoori Y. Thermophysical properties of ionic liquid, 1pentyl-3-methylimidazolium chloride in water at different temperatures. International Journal of Thermophysics 2009;30 499-514.

[36] Shekaari H, Mousavi SS. Osmotic coefficients and refractive indices of aqueous solutions of ionic liquids containing 1-butyl-3-methylimidazolium halide at $\mathrm{T}=(298.15$ to 328.15) K. Journal of Chemical and Engineering Data 2009;54 823-829.

[37] Shekaari H, Armanfar E. Physical properties of aqueous solutions of ionic liquid, 1propyl-3-methylimidazolium methyl sulfate, at $\mathrm{T}=(298.15$ to 328.15$) \mathrm{K}$. Journal of Chemical and Engineering Data 2010;55 765-772.

[38] Sardroodi JJ, Atabay M, Azamat J. Isopiestic determination of the osmotic coefficient and vapour pressure of N-R-4-(N,N-dimethylamino)pyridinium tetrafluoroborate $(\mathrm{R}$ $=\mathrm{C} 4 \mathrm{H} 9, \mathrm{C} 5 \mathrm{H} 11, \mathrm{C} 6 \mathrm{H} 13)$ in the ethanol solution at $\mathrm{T}=298.15 \mathrm{~K}$. The Journal of Chemical Thermodynamics 2012;49 70-74.

[39] Archer DG. Thermodynamic properties of the $\mathrm{NaBr}+\mathrm{H} 2 \mathrm{O}$ System. Journal of Physical and Chemical Reference Data 1991;20 509-555.

[40] Archer DG. Thermodynamic properties of the $\mathrm{NaCl}+\mathrm{H} 2 \mathrm{O}$ system. II. Thermodynamic properties of $\mathrm{NaCl}(\mathrm{aq}), \mathrm{NaCl} \cdot 2 \mathrm{H} 2(\mathrm{cr})$, and phase equilibria. Journal of Physical and Chemical Reference Data 1992;21 793-829.

[41] Shekaari H, Zafarani-Moattar MT. Osmotic coefficients of some imidazolium based ionic liquids in water and acetonitrile at temperature $318.15 \mathrm{~K}$. Fluid Phase Equilibria 2007;254 198-203. 
[42] Nasirzadeh K, Neueder R, Kunz W. Vapor pressures, osmotic and activity coefficients for ( $\mathrm{LiBr}+$ acetonitrile) between the temperatures (298.15 and 343.15) K. The Journal of Chemical Thermodynamics 2004;36 511-517.

[43] Nasirzadeh K, Neueder R, Kunz W. Vapor pressures, osmotic and activity coefficients of electrolytes in protic solvents at different temperatures. 2. Lithium bromide in ethanol. Journal of Solution Chemistry 2004;33 1429-1446.

[44] Nasirzadeh K, Neueder R, Kunz W. Vapor pressures, osmotic and activity coefficients of electrolytes in protic solvents at different temperatures. 3. Lithium bromide in 2-propanol. Journal of Solution Chemistry. 2005;34 9-24.

[45] Nasirzadeh K, Neueder R, Kunz W. Vapor pressures and osmotic coefficients of aqueous $\mathrm{LiOH}$ solutions at temperatures ranging from 298.15 to $363.15 \mathrm{~K}$. Industrial and Engineering Chemistry Research 2005;44 3807-3814.

[46] Sadeghi R, Ebrahimi N. Ionic association and solvation of the ionic liquid 1-hexyl-3methylimidazolium chloride in molecular solvents revealed by vapor pressure osmometry, conductometry, volumetry, and acoustic measurements. The Journal of Physical Chemistry B 2011;115 13227-13240.

[47] González B, Calvar N, Domínguez A, Macedo EA. Osmotic coefficients of aqueous solutions of four ionic liquids at $\mathrm{T}=(313.15$ and 333.15$) \mathrm{K}$. The Journal of Chemical Thermodynamics 2008;40 1346-1351.

[48] Calvar N, González B, Domínguez A, Macedo EA. Osmotic coefficients of binary mixtures of 1-butyl-3-methylimidazolium methylsulfate and 1,3-dimethylimidazolium methylsulfate with alcohols at $\mathrm{T}=323.15 \mathrm{~K}$. The Journal of Chemical Thermodynamics 2009;41 617-622.

[49] Calvar N, González B, Domínguez A, Macedo EA. Vapour pressures and osmotic coefficients of binary mixtures of 1-ethyl-3-methylimidazolium ethylsulfate and 1-ethyl-3-methylpyridinium ethylsulfate with alcohols at $\mathrm{T}=323.15 \mathrm{~K}$. The Journal of Chemical Thermodynamics 2009;41 1439-1445.

[50] Calvar N, González B, Domínguez A, Macedo EA. Osmotic coefficients of binary mixtures of four ionic liquids with ethanol or water at $\mathrm{T}=(313.15$ and 333.15$) \mathrm{K}$. The Journal of Chemical Thermodynamics 2009;41 11-16.

[51] Calvar N, Gómez E, Domínguez A, Macedo EA. Vapour pressures, osmotic and activity coefficients for binary mixtures containing (1-ethylpyridinium ethylsulfate + several alcohols) at $\mathrm{T}=323.15 \mathrm{~K}$. The Journal of Chemical Thermodynamics 2010;42 625-630.

[52] Gómez E, Calvar N, Domínguez A, Macedo EA. Measurement and modeling of osmotic coefficients of binary mixtures (alcohol + 1,3-dimethylpyridinium methylsulfate) at $\mathrm{T}=323.15 \mathrm{~K}$. The Journal of Chemical Thermodynamics 2011;43 908-913.

[53] Calvar N, Gómez E, Domínguez A, Macedo EA. Determination and modelling of osmotic coefficients and vapour pressures of binary systems 1- and 2-propanol with 
CnmimNTf2 ionic liquids ( $\mathrm{n}=2,3$, and 4$)$ at $\mathrm{T}=323.15 \mathrm{~K}$. The Journal of Chemical Thermodynamics 2011;43 1256-1262.

[54] Calvar N, Gómez E, Domínguez A, Macedo EA. Study of the influence of the structure of the alcohol on vapor pressures and osmotic coefficients of binary mixtures alcohol + 1-hexyl-3-methylimidazolium bis(trifluoromethylsulfonyl)imide at $\mathrm{T}=323.15$ K. Fluid Phase Equilibria 2012;313 38-45.

[55] Calvar N, González EJ, Domínguez A, Macedo EA. Acoustic, volumetric and osmotic properties of binary mixtures containing the ionic liquid 1-butyl-3-methylimidazolium dicyanamide mixed with primary and secondary alcohols. The Journal of Chemical Thermodynamics 2012;50 19-29.

[56] Abrams DS, Prausnitz, JM. Statistical thermodynamics of liquid mixtures: A new expression for the excess Gibbs energy of partly or completely miscible systems. AIChE Journal 1975;21 116-128.

[57] Renon, H.; Prausnitz, JM. Local compositions in thermodynamic excess functions for liquid mixtures. AIChE Journal 1968;14 135-144.

[58] Chen CC, Evans LB. A local composition model for the excess Gibbs energy of aqueous electrolyte systems. AIChE Journal 1986;32 444-454.

[59] Haghtalab A, Vera J. A nonrandom factor model for the excess Gibbs energy of electrolyte solutions. AIChE Journal 1988;34 803-812.

[60] Jaretum A, Aly G. New local composition model for electrolyte solutions: single solvent, single electrolyte systems. Fluid Phase Equilibria 1999;163 175-193.

[61] Papiconomou N, Simonin JP, Bernard O, Kunz W. MSA-NRTL model for the description of the thermodynamic properties of electrolyte solutions. Physical Chemistry Chemical Physics 2002;4 4435-4443.

[62] Zhao E, Yu M, Sauve RE, Khoshkbarchi MK. Extension of the Wilson model to electrolyte solutions. Fluid Phase Equilibria 2000;173 161-175.

[63] Domanska U, Bogel-Łukasik E. Measurements and correlation of the (solid + liquid) equilibria of [1-decyl-3-methylimidazolium chloride + alcohols (C2-C12)]. Industrial and Engineering Chemistry Research 2003;42, 6986-6992.

[64] Domanska U, Bogel-Łukasik E, Bogel-Łukasik R. Solubility of 1-dodecyl-3-methylimidazolium chloride in alcohols (C2-C12). Journal of Physical Chemistry B 2003;107 1858-1863.

[65] Kato R, Krummen M, Gmehling J. Measurement and correlation of vapor-liquid equilibria and excess enthalpies of binary systems containing ionic liquids and hydrocarbons. Fluid Phase Equilibria 2004;224 47-54.

[66] Banerjee T, Singh MK, Sahoo RK, Khanna A. Volume, surface and UNIQUAC interaction parameters for imidazolium based ionic liquids via Polarizable Continuum Model. Fluid Phase Equilibria 2005;234 64-76. 
[67] Simoni LD, Lin Y, Brennecke JF, Stadtherr MA. Modeling liquid-liquid equilibrium of ionic liquid systems with NRTL, electrolyte-NRTL, and UNIQUAC. Industrial and Engineering Chemistry Research 2008;47 256-272.

[68] Domanska D, Mazurowska L. Solubility of 1,3-dialkylimidazolium chloride or hexafluorophosphate or methylsulfonate in organic solvents: effect of the anions on solubility. Fluid Phase Equilibria 2004;221 73-82.

[69] Carneiro AP, Rodríguez O, Macedo EA. Solubility of monosaccharides in ionic liquids - Experimental data and modeling. Fluid Phase Equilibria 2012;314 22- 28.

[70] Carneiro AP, Rodríguez O, Macedo EA. Solubility of xylitol and sorbitol in ionic liquids - Experimental data and modeling. The Journal of Chemical Thermodynamics 2012; http://dx.doi.org/10.1016/j.jct.2012.05.020

[71] Calvar N, González B, Gómez E, Domínguez A. Vapor-liquid equilibria for the ternary system ethanol + water + 1-butyl-3-methylimidazolium chloride and the corresponding binary systems at $101.3 \mathrm{kPa}$. Journal of Chemical and Engineering Data 2006;51 2178-2181.

[72] Calvar N, González B, Gómez E, Domínguez A. Study of the behavior of the azeotropic mixture ethanol-water with imidazolium-based ionic liquids. Fluid Phase Equilibria 2007;259 51-56

[73] Calvar N, González B, Gómez E, Domínguez A. Vapor-liquid equilibria for the ternary system ethanol + water + 1-ethyl-3-methylimidazolium ethylsulfate and the corresponding binary systems containing the ionic liquid at $101.3 \mathrm{kPa}$. Journal of Chemical and Engineering Data 2008;53 820-825.

[74] Calvar N, González B, Gómez E, Domínguez A. Vapor-liquid equilibria for the ternary system ethanol + water + 1-butyl-3-methylimidazolium methylsulfate and the corresponding binary systems at $101.3 \mathrm{kPa}$. Journal of Chemical and Engineering Data 2009;54 1004-1008.

[75] Calvar N, Gómez E, González B, Domínguez A. Experimental vapor-liquid equilibria for the ternary system ethanol + water + 1-ethyl-3-methylpyridinium ethylsulfate and the corresponding binary systems at $101.3 \mathrm{kPa}$ : Study of the Effect of the Cation. Journal of Chemical and Engineering Data 2010;55 2786-2791.

[76] Safarov J, Verevkin SP, Bich E, Heintz A. Vapor pressures and activity coefficients of n-alcohols and benzene in binary mixtures with 1-methyl-3-butylimidazolium octyl sulfate and 1-methyl-3-octylimidazolium tetrafluoroborate. Journal of Chemical and Engineering Data 2006;51 518-525.

[77] Shekaari H, Mousavi SS. Measurement and modeling of osmotic coefficients of aqueous solution of ionic liquids using vapor pressure osmometry method. Fluid Phase Equilibria 2009;279 73-79.

[78] Orchillés AV, Miguel PJ, González-Alfaro V, Vercher E, Martínez-Andreu A. 1-Ethyl-3-methylimidazolium dicyanamide as a very efficient entrainer for the extractive 
distillation of the acetone + methanol system. Journal of Chemical and Engineering Data 2012;57 394-399.

[79] Jongmans MTG, Schuur B, de Haan AB. Binary and ternary LLE data of the system (ethylbenzene + styrene + 1-ethyl-3-methylimidazolium thiocyanate) and binary VLE data of the system (styrene + 1-ethyl-3-methylimidazolium thiocyanate). The Journal of Chemical Thermodynamics 2012;47 234-240.

[80] Domanska U, Marciniak A. Liquid phase behaviour of 1-butyl-3-methylimidazolium 2-(2-methoxyethoxy)-ethylsulfate with organic solvents and water. Green Chemistry $2007 ; 9$ 262-266.

[81] Maia FM, Rodríguez O, Macedo EA. LLE for (water + ionic liquid) binary systems using [Cxmim][BF4] $(x=6,8)$ ionic liquids. Fluid Phase Equilibria 2010;296 184-191.

[82] Arce A, Rodríguez O, Soto A. Tert-Amyl Ethyl Ether separation from its mixtures with ethanol using the 1-butyl-3-methylimidazolium trifluoromethanesulfonate ionic liquid: Liquid-Liquid Equilibrium. Industrial and Engineering Chemistry Research 2004;43 8323-8327.

[83] Arce A, Rodríguez O, Soto A. A comparative study on solvents for separation of tertamyl ethyl ether and ethanol mixtures. New experimental data for 1-ethyl-3-methyl imidazolium ethyl sulfate ionic liquid", Chemical Engineering Science 2006;61 69296935.

[84] Wytze Meindersma G, Podt AJG, de Haan AB. Ternary liquid-liquid equilibria for mixtures of toluene + n-heptane + an ionic liquid. Fluid Phase Equilibria 2006;247 158-168.

[85] $\mathrm{Hu}$ X, Yu J, Liu H. Liquid-Liquid Equilibria of the system 1-(2-Hydroxyethyl)-3methylimidozolium tetrafluoroborate or 1-(2-hydroxyethyl)-2,3-dimethylimidozolium tetrafluoroborate + water + 1-butanol at 293.15 K. Journal of Chemical and Engineering Data 2006;51 691-695.

[86] Chen CC, Boston JF, Evans LB, Britt HI. Local composition model for excess Gibbs energy of electrolyte systems. Part I: Single solvent, single completely dissociated electrolyte systems. AICHE Journal 1982;28 588-596.

[87] Sardroodi JJ, Zafarani-Moattar MT. Vapor pressures and apparent molal volumes of the solutions of $\mathrm{ZnCl} 2$ in ethanol at 298.15 K. Fluid Phase Equilibria 2005;230 64-71.

[88] Peng DY, Robinson DB. A New Two-Constant Equation of State. Industrial \& Engineering Chemistry Fundamentals 1976;15 59-64.

[89] Valderrama JO, Robles PA. Critical properties, normal boiling temperatures, and acentric factors of fifty ionic liquids. Industrial \& Engineering Chemistry Research 2007;46 1338-1344. 
[90] Valderrama JO, Sanga WW, Lazzu JA. Critical properties, normal boiling temperature, and acentric factor of another 200 ionic liquids. Industrial \& Engineering Chemistry Research 2008;47 1318-1330.

[91] Valderrama JO, Rojas RE. Critical properties of ionic liquids. Revisited. Industrial \& Engineering Chemistry Research 2009;48 6890-6900.

[92] Valderrama JO, Forero LA, Rojas RE, Serena L. Critical properties and normal boiling temperature of ionic liquids. Update and a new consistency test. Industrial \& Engineering Chemistry Research 2012;51 7838-7844.

[93] Alvarez VH, Aznar M. Thermodynamic modeling of vapor-liquid equilibrium of binary systems ionic liquid+supercritical $\{\mathrm{CO} 2$ or $\mathrm{CHF}\}$ and ionic liquid+hydrocarbons using Peng-Robinson equation of state. Journal of the Chinese Institute of Chemical Engineers 2008;39 353-360.

[94] Arce PF, Robles PA, Graber TA, Aznar M. Modeling of high-pressure vapor-liquid equilibrium in ionic liquids+gas systems using the PRSV equation of state. Fluid Phase Equilibria 2010;295 9-16.

[95] Yazdizadeh M, Rahmani F, Forghani AA. Thermodynamic modeling of CO2 solubility in ionic liquid ([Cnmim] [Tf2N]; $\mathrm{n}=2,4,6,8)$ with using Wong-Sandler mixing rule, Peng-Rabinson equation of state (EOS) and differential evolution (DE) method. Korean Journal of Chemical Engineering 2011;28 246-251.

[96] Mattedi S, Carvalho PJ, Coutinho JAP, Alvarez VH, Iglesias M. High pressure CO2 solubility in N-methyl-2-hydroxyethylammonium protic ionic liquids. Journal of Supercritical Fluids 2011;56 224-230.

[97] Shariati A, Peters CJ. High-pressure phase behavior of systems with ionic liquids: measurements and modeling of the binary system fluoroform + 1-ethyl-3-methylimidazolium hexafluorophosphate. Journal of Supercritical Fluids 2003;25 109-117.

[98] Song HN, Lee BC, Lim JS. Measurement of CO2 solubility in ionic liquids: [BMP] [TfO] and $[\mathrm{P} 14,6,6,6][\mathrm{Tf} 2 \mathrm{~N}]$ by measuring bubble-point pressure. Journal of Chemical Engineering Data 2010;55 891-896.

[99] Ren W, Scurto AM. Phase equilibria of imidazolium ionic liquids and the refrigerant gas, 1,1,1,2-tetrafluoroethane (R-134a). Fluid Phase Equilibria 2009;286 1-7.

[100] Hwang S, Park Y, Park K. Measurement and prediction of phase behaviour for 1-alkyl-3-methylimidazolium tetrafluoroborate and carbon dioxide: Effect of alkyl chain length in imidazolium cation. Journal of Chemical Thermodynamics 2011;43 339-343.

[101] Bogel-Łukasik R, Matkowska D, Bogel-Łukasik E, Hofman T. Isothermal vapour-liquid equilibria in the binary and ternary systems consisting of an ionic liquid, 1-propanol and CO2. Fluid Phase Equilibria 2010;293 168-174. 
[102] Bogel-Łukasik R, Matkowska D, Zakrzewska ME, Bogel-Łukasik E, Hofman T. The phase envelopes of alternative solvents (ionic liquid, CO2) and building blocks of biomass origin (lactic acid, propionic acid). Fluid Phase Equilibria 2010;295 177-185.

[103] Shin EK, Lee BC, Lim JS. High-pressure solubilities of carbon dioxide in ionic liquids: 1-Alkyl-3-methylimidazolium bis(trifluoromethylsulfonyl)imide. Journal of Supercritical Fluids 2008;45 282-292.

[104] Alvarez VH, Mattedi S, Aznar M. Isobaric (vapor+liquid) equilibria of 1-ethyl-3methylimidazolium ethylsulfate plus (propionaldehyde or valeraldehyde): Experimental data and prediction. Journal of Chemical Thermodynamics 2011;43 895-900.

[105] Soave G. Equilibrium constants from a modified Redlich-Kwong equation of state. Chemical Engineering Science 1972;27 1197-1203.

[106] Shiflett MB, Yokozeki A. Solubilities and diffusivities of carbon dioxide in ionic liquids: [bmim][PF6] and [bmim][BF4]. Industrial \& Engineering Chemistry Research 2005;44 4453-4464.

[107] Yokozeki A, Shiflett MB. Ammonia solubilities in room-temperature ionic liquids. Industrial \& Engineering Chemistry Research 2007;46 1605-1610.

[108] Yokozeki A, Shiflett MB. Vapor-liquid equilibria of ammonia+ionic liquid mixtures. Applied Energy 2007;84 1258-1273.

[109] Shiflett MB, Yokozeki A. Chemical absorption of sulfur dioxide in room-temperature ionic liquids. Industrial \& Engineering Chemistry Research 2010;49 1370-1377.

[110] Yokozeki A, Shiflett MB. Water solubility in ionic liquids and application to absorption cycles. Industrial \& Engineering Chemistry Research 2010;49 9496-9503.

[111] Yokozeki A, Shiflett MB. Hydrogen purification using room-temperature ionic liquids. Applied Energy 2007;84 351-361.

[112] Shiflett MB, Yokozeki A. Separation of carbon dioxide and sulfur dioxide using room-temperature ionic liquid [bmim][MeSO4]. Energy Fuels 2010;24 1001-1008.

[113] Shiflett MB, Yokozeki A. Separation of CO2 and H2S using room-temperature ionic liquid [bmim][PF6]. Fluid Phase Equilibria 2010;294 105-113.

[114] Shiflett MB, Niehaus AMS, Yokozeki A. Separation of CO2 and H2S using room-temperature ionic liquid [bmim][MeSO4]. Journal of Chemical Engineering Data 2010;5 4785-4793.

[115] Shiflett MB, Elliott BA, Niehaus AMS, Yokozeki A. Separation of N2O and CO2 using room-temperature ionic liquid [bmim][Ac]. Separation Science and Technology 2012;47 411-421.

[116] Chapman WG, Gubbins KE, Jackson G, Radosz M. SAFT: Equation-of-state solution model for associating fluids. Fluid Phase Equilibria 1989;52 31-38. 
[117] Wertheim MS. Fluids with highly directional attractive forces. I. Statistical thermodynamics. Journal of Statistical Physics 1984;35 19-34.

[118] Wertheim MS. Fluids with highly directional attractive forces. II. Thermodynamic perturbation theory and integral equations. Journal of Statistical Physics 1984;35 $35-47$.

[119] Wertheim MS. Fluids with highly directional attractive forces. III. Multiple attraction sites. Journal of Statistical Physics 1986;42 459-476.

[120] Wertheim MS. Fluids with highly directional attractive forces. IV. Equilibrium polymerization. Journal of Statistical Physics 1986;42 477-492.

[121] Kroon MC, Karakatsani EK, Economou IG, Witkamp GJ, Peters CJ. Modeling of the carbon dioxide solubility in imidazolium-based ionic liquids with the tPC-PSAFT equation of state. Journal of Physical Chemistry B 2006;110 9262-9269.

[122] Karakatsani EK, Economou IG, Kroon MC, Peters CJ, Witkamp GJ. tPC-PSAFT Modeling of gas solubility in imidazolium-based ionic liquids. Journal of Physical Chemistry C 2007;111 15487-15492.

[123] Karakatsani EK, Economou IG. Phase equilibrium calculations for multi-component polar fluid mixtures with tPC-PSAFT. Fluid Phase Equilibria 2007;261 265-271.

[124] Economou IG, Karakatsani EK, Logotheti G, Ramos J, Vanin, A.A. Multi-scale modeling of structure, dynamic and thermodynamic properties of imidazolium-based ionic liquids: Ab initio DFT calculations, molecular simulation and equation of state predictions. Oil \& Gas Science and Technology 2008;63 283-293.

[125] Karakatsani EK, Economou IG, Kroon MC, Bermejo MD, Peters CJ, Witkamp GJ. Equation of state modeling of the phase equilibria of ionic liquid mixtures at low and high pressure. Physical Chemistry Chemical Physics 2008;10 6160-6168.

[126] Andreu JS, Vega LF. Capturing the solubility behavior of CO2 in ionic liquids by a simple model. Journal of Physical Chemistry C 2007;111 16028-16034.

[127] Andreu JS, Vega LF. Modeling the solubility behavior of $\mathrm{CO}(2), \mathrm{H}(2)$, and $\mathrm{Xe}$ in $[C(n)-\operatorname{mim}][\mathrm{Tf}(2) \mathrm{N}]$ ionic liquids. Journal of Physical Chemistry B 2008;112 15398-15406.

[128] Llovell F, Valente E, Vilaseca O, Vega LF. Modeling complex associating mixtures with [Cn-mim][Tf2N] ionic liquids: predictions from the soft-SAFT equation. Journal of Physical Chemistry B 2011;115 4387-4398.

[129] Ji X, Adidharma H. Thermodynamic modeling of CO2 solubility in ionic liquid with heterosegmented statistical associating fluid theory. Fluid Phase Equilibria 2010;293 141-150.

[130] Paduszyński K, Chiyen J, Ramjugernath D, Letcher TM, Domańska U. Liquid-liquid phase equilibrium of (piperidinium-based ionic liquid+an alcohol) binary systems and modelling with NRHB and PCP-SAFT. Fluid Phase Equilibria 2011;305 43-52. 
[131] Paduszyński K, Domańska U. Solubility of aliphatic hydrocarbons in piperidinium ionic liquids: measurements and modeling in terms of perturbed-chain statistical associating fluid theory and nonrandom hydrogen-bonding theory. Journal of Physical Chemistry B 2011;115 12537-12548.

[132] Tsioptsias C, Tsivintzelis I, Panayiotou C. Equation-of-state modeling of mixtures with ionic liquids. Physical Chemistry Chemical Physics 2010;12 4843-4851.

[133] Panayiotou C, Tsivintzelis I, Economou IG. Nonrandom hydrogen-bonding model of fluids and their mixtures. 2. Multicomponent mixtures. Industrial \& Engineering Chemistry Research 2007;46 2628-2636.

[134] Wang T, Peng C, Liu H, Hu Y. Description of the pVT behavior of ionic liquids and the solubility of gases in ionic liquids using an equation of state. Fluid Phase Equilibria 2006;250 150-157.

[135] Hu Y, Liu H, Prausnitz, JM. Equation of state for fluids containing chainlike molecules. Journal of Chemical Physics 1996;104 396-404.

[136] Breure B, Bottini SB, Witkamp GJ, Peters CJ. Thermodynamic modeling of the phase behavior of binary systems of ionic liquids and carbon dioxide with the group contribution equation of state. Journal of Physical Chemistry B 2007;111 14265-14270.

[137] Maia FM, Tsivintzelis I, Rodrígez O, Macedo EA, Kontogeorgis GM. Equation of state modelling of systems with ionic liquids: Literature review and application with the Cubic Plus Association (CPA) model. Fluid Phase Equilibria; 332, 128-143.

[138] Kontogeorgis GM, Voutsas EC, Yakoumis IV, Tassios DP. An equation of state for associating fluids. Industrial \& Engineering Chemistry Research 1996;35 4310-4318. 